\title{
First record on the development of the larva of the basally branching nemertean species Carinina ochracea (Palaeonemertea)
}

\author{
Jörn von Döhren ${ }^{*}$
}

\begin{abstract}
Nemertea are a clade of unsegmented, vermiform, mostly marine Spiralia. While it is generally accepted that Nemertea develop via a pelagic larval stage there is considerable uncertainty about its characteristic, ancestral features. The uncertainty is mainly due to highly disparate larval types in the derived clade Neonemertea and the scarce information on the larval types of Palaeonemertea, the basal-most branching clade of Nemertea. To remedy this shortage of data the early larval development of a member of the palaeonemertean genus Carinina, Carinina ochracea, is described for the first time. Congruently to what has been described in other palaeonemertean species the larva of C. ochracea is uniformly ciliated along with an apical tuft of elongated cilia housed in an epidermal depression, the apical pit. A pair of frontal epidermal invaginations present bilaterally of the apical pit has been shown in other palaeonemertean larvae as well. Following gastrulation the blastopore is shifted to the ventral side of the body to become the mouth opening. A pair of simple unbranched nephridia that is situated on both sides of the mouth opening completes the list of structures documented for palaeonemertean larvae. Formation of the anal opening was not observed during this study. The presence of a single pigmented ventral eye was hitherto reported from the larva of Carinoma species only. The presented results complement the record of larval types found in Palaeonemertea and will serve as a reference for subsequent studies on the development of internal structures in palaeonemertean species.
\end{abstract}

Keywords: Lophotrochozoa, Nemertea, Development, Larva, Reproductive biology

\section{Background}

The spiralian clade Nemertea comprises approximately 1275 described species that are mostly marine, nocturnal predators [22]. Apart from some symbiotic species and few groups of species that inhabit the pelagic zones of all oceans the majority of species inhabits benthic and endobenthic cryptic habitats [11]. While being vagile, creeping adults most nemerteans develop from one of several types of pelagic larvae of which the pilidium larva might be the most well-known [24]. The pilidium larva is typical of the nemertean clade Pilidiophora comprising Heteronemertea and Hubrechtiidae the latter having formerly been classified as palaeonemertean [1, 2, 23, 38]. The pilidium larva shows maximally indirect development

*Correspondence: jdoehren@evolution.uni-bonn.de Institute of Evolutionary Biology and Ecology, University of Bonn, An der Immenburg 1, 53121 Bonn, Germany with most of the juvenile developing inside the larval epidermis from distinct primordial structures termed imaginal discs. Larval development in Pilidiophora results in a catastrophic metamorphosis in which the majority of the larval tissues is shed and subsequently ingested $[6,24]$. The remaining nemertean groups, namely Hoplonemertea and Palaeonemertea (sensu stricto, i.e. without Hubrechtiidae), have been reported to possess a planuliform larva which gradually transforms into the juvenile [10, 11, 30, 40]. Recently however, in Hoplonemertea the larva has been shown not only to replace its epidermis during development but also to possess invaginations that are arguably homologous to the pilidiophoran imaginal discs [13-15, 25, 27]. As a consequence, the larval type of Hoplonemertea has been re-named decidula larva, alluding to the presence of a transitory larval epidermis $[15,25,27]$. While there is comparably extensive data on the larvae of both Pilidiophora and 
Hoplonemertea comparatively little is known on the diversity of larvae in palaeonemertean species $[25,26$, 30, 40 and references therein]. Detailed information is restricted to accounts on species of the genera Cephalothrix (Procephalothrix) (four species), Tubulanus (two species), and Carinoma (two species) [3, 8, 17, 28, 29, 33]. Larvae of species of the genera Callinera and Carinina have only been pictured; detailed descriptions are absent $[7,21,26,40]$. The larval type of the palaeonemertean species Carinoma tremaphoros has been characterized as distinctly different from larvae of Hoplonemertea and Pilidiophora and subsequently termed 'hidden' trochophore larva more recently $[11,18,25,26,28]$. Larvae of C. tremaphoros and Carinoma mutabilis possess a single latero-ventral eye $[3,28,30,40]$. Larvae described in other palaeonemertean species however, are notably different. While the larvae of Cephalothrix species possess a pair of pigmented cerebral eyes the same are absent from the larvae of Tubulanus and Callinera species [17, 21, 30, 33]. Furthermore, nephridial organs, although having only been investigated in larvae of Cephalothrix and Carinoma species show some ultrastructural differences [3]. Thus, from the sparse information available, it becomes evident that diversity of larval features in palaeonemertean species might be higher than hitherto appreciated. In order to complement the knowledge on larval types in Palaeonemertea the larva of the palaeonemertean species Carinina ochracea is described. The genus Carinina has classically been regarded as the most basally branching lineage of Nemertea arguably representing ancestral states in the majority of anatomical features [5]. Furthermore, of the four distinct palaeonemertean lineages recovered in most recent phylogenetic analyses Carinina is the only one without detailed data on development at hand. Presently, only few published images of this enigmatic representative of Palaeonemertea are available $[26,40]$. The following description is based on light and confocal microscopic data and includes a timeline of the formation of characteristic larval features. The results presented are intended to represent a future reference that preludes a series of studies on the development of different organ systems in nemertean worms.

\section{Methods}

\section{Species and collection site}

Sexually mature males and females of Carinina ochracea Sundberg, Chernyshev, Kajihara, Kånneby \& Strand, 2009 (Palaeonemertea, Nemertea) were obtained by digging them up from a sandflat near Pouldohan (Dpt. Finistère, France; $47^{\circ} 50^{\prime} \mathrm{N} 3^{\circ} 53^{\prime} \mathrm{W}$ ) at low-tide between May and August of the years 2011-2015 during visits at the Station de Biologie Marine de Concarneau (Dpt. Finistère, France). Animals were brought to the Institute of
Evolutionary Biology and Ecology of the University of Bonn (Germany) where they were kept at $18^{\circ} \mathrm{C}$ in plastic boxes with lid (approx. $1.5 \mathrm{l}$ capacity) filled with sand from the collecting site and artificial sea water until gametes were obtained. Animals were neither fed nor sorted by sex. Water was changed once per week.

\section{Obtaining gametes and larval culture}

Oocytes were obtained at $18{ }^{\circ} \mathrm{C}$ by dissecting the gonad region of females in ultra-filtered $(0.2 \mu \mathrm{m})$ natural sea water from the collecting site under the dissecting microscope with the aid of fine forceps. Subsequently the oocytes were passed through a $100 \mu \mathrm{m}$ mesh, only the oocytes that were larger than $100 \mu \mathrm{m}$ were kept for fertilization. Fertilization was accomplished with sperm suspension obtained by dissecting the gonad region of males under the dissecting microscope with the aid of a razor blade. Sperm was diluted in ultra-filtered natural sea water from the collecting site and added to the oocytes in glass bowls (approx. $200 \mathrm{ml}$ capacity) filled with approx. $100 \mathrm{ml}$ of ultra-filtrated natural sea water from the collecting site. During the course of the study several males and females were used to obtain numerous batches of larvae. Developing embryos/larvae were kept at $18{ }^{\circ} \mathrm{C}$ at a light-dark cycle of 16:8 h. During the first 2 days of development water was changed daily with ultra-filtrated natural sea water from the collecting site. Afterwards, the larvae were transferred to plastic boxes with a lid (approx. $1.5 \mathrm{l}$ capacity) filled with $1 \mathrm{l}$ of a mixture of equal parts of natural sea water from the collecting site filtered through a $20 \mu \mathrm{m}$ mesh and artificial sea water. Water changes by reverse filtering of half of the total volume through a $50 \mu \mathrm{m}$ mesh were done 3 times a week with the sea water mixture mentioned above. Although several food items [including Tetraselmis subcordiformis (Wille) Butcher, 1959 and Saccharomyces cerevisiae Meyen ex E.C. Hansen, 1883] were offered the larvae ceased to develop further after the 10th day and disappeared from the culture after approximately 3 weeks.

\section{Sampling of larval stages}

Sampling started after $20 \mathrm{~h}$ of development to avoid selection of malformed developmental stages. Only normal looking, rounded specimens showing regular movement (see below) were chosen. Larvae were fixed at $20 \mathrm{~h}$ post fertilization (hpf) and 1, 2, 3, 4, 5, 7, and 10 days post fertilization (dpf). Prior to fixation larvae were washed with 3 changes of ultra-filtrated artificial sea water. From the 3rd day of development on larvae were anesthetized/ paralyzed with ultra-filtrated $(0.2 \mu \mathrm{m}) 3.5 \% \mathrm{MgCl}_{2}$ [prepared from equal amounts of artificial sea water and $7 \%$ $\mathrm{MgCl}_{2}$ (VWR Chemicals) solution in distilled water] at room temperature for $15 \mathrm{~min}$. 


\section{Fixation and preparation of whole mounts for light microscopy}

For whole mount light microscopy larvae were fixed in small glass vials in $2.5 \%$ glutaraldehyde (GA, from a $10 \%$ GA stock solution) in TEM-PBS (0.05 M phospate buffer saline, with $0.3 \mathrm{M} \mathrm{NaCl}, \mathrm{pH} 7.2$ ) with traces of Ruthenium red for $30 \mathrm{~min}$ at $4{ }^{\circ} \mathrm{C}$. Subsequently the specimens were rinsed several times over the period of $24 \mathrm{~h}$ in the same buffer as had been used to dilute the GA. Alternatively, some larvae were fixed in small glass vials in $4 \%$ para-formaldehyde (PFA, freshly prepared from a $16 \%$ PFA stock solution), $0.5 \%$ glutaraldehyde, [from a $10 \%$ GA stock solution (Electron Microscope Science)] in $0.05 \mathrm{M}$ Tris, $0.3 \mathrm{M} \mathrm{NaCl}$ buffer $\left(\mathrm{pH} \mathrm{10.2)}\right.$ at $4{ }^{\circ} \mathrm{C}$ for several weeks. The latter fixation had been intended for use in a different study but in order to increase the number of different fertilization batches examined the larvae were also utilized for whole mount light microscopy herein. Therefore, in the PFA-GA fixed animals, Ruthenium red was added with the washing buffer (TEM-PBS) for $45 \mathrm{~min}$ and subsequently washed in the same manner as GA fixed specimens. All specimens were postfixed in $1 \%$ osmium tetroxide $\left(\mathrm{OsO}_{4}\right)$ buffered in TEM-PBS at $4{ }^{\circ} \mathrm{C}$ for $45 \mathrm{~min}$. Subsequently they were dehydrated in a graded acetone series followed by propylene oxide and finally transferred into araldite. Entire larvae were mounted as whole mounts in araldite on glass slides. The whole mount preparations were examined an Olympus BX 51 Light Mircoscope equipped with a mounted digital camera (Coloview Soft Imaging System Camera) with differential interference contrast settings. Pictures were digitally recorded with cellD (Soft Imaging Systems). Three to four different focal planes were recorded from each specimen. Additionally, a picture without specimen was taken for every focal series for subsequent flatfield correction.

\section{Immunohistochemistry and confocal laser scanning microscopy}

For immunohistochemical labeling larvae were fixed at $18-20{ }^{\circ} \mathrm{C}$ in ultra-filtered $(0.2 \mu \mathrm{m}), 4 \%$ para-formaldehyde solution [PFA, freshly prepared from a $16 \%$ PFA solution (Electron Microscope Science), and artificial sea water] for $30 \mathrm{~min}$ in glass bowls (approx. $4 \mathrm{ml}$ capacity) coated with Sigmacote (Sigma-Aldrich) to avoid extensive sticking of the larvae to the container walls and bottom. To stop the fixation process larvae were washed in 3 changes of $10 \mathrm{~min}$ in $0.1 \mathrm{M}$ phosphate buffer saline (PBS) at $\mathrm{pH} 7.4$ with $0.01 \% \mathrm{NaN}_{3}$ (Carl Roth) added. Larvae were stored in the same buffer in siliconized polypropylene microcentrifuge tubes $(1.7 \mathrm{ml}$ capacity) (SigmaAldrich). Prior to staining, some larvae (20 h and 3 days post fertilization) were incubated in Image It FX signal enhancer (Molecular Probes) at a concentration according to the manufacturer's protocol for an hour at room temperature. Larvae were washed in 3 changes of PBT [PBS with $0.3 \%$ Triton X-100 (Sigma-Aldrich) added] for 10 min each prior to blocking in PBT with $10 \%$ normal goat serum (NGS, Sigma-Aldrich) for $2 \mathrm{~h}$ at $18^{\circ} \mathrm{C}$. Subsequently, the larvae were incubated with the primary antibody diluted in PBT at $18{ }^{\circ} \mathrm{C}$ overnight on a rocking table. The antibody against acetylated $\alpha$-tubulin was produced in mouse (T7451, Sigma) and was applied at a dilution of 1:300. It was removed by three quick washes followed by three washes of $15 \mathrm{~min}$ each in PBT. The secondary antibody was goat anti mouse conjugated to either Alexa Fluor 488 (A11001, Invitrogen) or Alexa Fluor 633 (A21052, Invitrogen). It was applied in PBT at a dilution of 1:100. The secondary antibody was washed out using the same procedure as outlined for the primary antibody. After the final washing step the larvae were fastened to cover glasses (\#1, Thermo Scientific) coated with $0.01 \%$ Poly-L-lysine-hydrobromide (Sigma-Aldrich). The preparations were dehydrated using a graded series of Isopropanol (70, 85, $95 \%$, twice $100 \%)$ for 1 min each followed by 3 changes of Murray Clear [ 1 part of Benzyl alcohol (Carl Roth) mixed with 2 parts of Benzyl benzoate (Sigma-Aldrich)] for $10 \mathrm{~min}$ each. The larvae were then mounted in Murray Clear using small pieces of modeling clay as spacers between glass slide and cover glass. The resulting gaps between glass slide and cover glass were sealed with nail polish. Larvae were allowed to clear over night at $4{ }^{\circ} \mathrm{C}$ before they were examined. To assess for unspecific binding of the secondary antibodies controls were run by omitting the primary antibody from the antibody staining procedure outlined above. For signal detection a Leica TCS/SPE confocal laser scanning system mounted on a Leica DM 2500 microscope was used. All images were recorded with a $40 \times$ dry objective with a numerical aperture (NA) of 0.75 with the pinhole diameter set to at airy disc size. Confocal stacks were recorded at $1024 \times 1024$ pixels at an image depth of 8-bit for $24 \mathrm{~h}$ and 10 day old larvae and 12-bit for $20 \mathrm{~h}$ and 3 day old larvae at a virtual section thickness of $0.88 \mu \mathrm{m}$.

\section{Image processing}

The focal planes taken from the osmium tetroxide stained whole mounts were projected into one image using the default setting of the extended depth of field (expert mode) plug-in [9] of the FIJI distribution package of ImageJ version $1.50 \mathrm{e}$ (Wayne Rasband, NIH). With the same program (FIJI) a flatfield correction was computed for each projected image. For image processing of the confocal image stacks the FIJI distribution package [42] of ImageJ version 1.50e (Wayne Rasband, NIH) was used. Selected sections of the stacks were projected, rotated, 
translated, cropped, and 12-bit depth projections were set to 8-bit depth. The background was set to black under visual control with the HiLo Lookup table. To enhance dim features a gamma correction of 0.8 was applied. Image plates and line drawings were assembled and labelled using Adobe Creative Suite 6 Illustrator and Photoshop.

\section{Results}

\section{Gametes and fertilization}

Natural spawning of Carinina ochracea never occurred in captivity. The ultrastructure and dimensions of the sperm cell has been erroneously described as the sperm cell of Tubulanus linearis (McIntosh, 1874) in von Döhren et al. [41]. Spermatozoa dissected from the testes become motile when diluted in sea water. Oocytes have an irregular outline when extracted from the gonad but start rounding up upon contact with sea water. They are invested with a thin, membranaceous vitelline envelope and show a single, germinal vesicle. There is no stalk-like cytoplasmic extension present opposite of the pole of the germinal vesicle. The maximum size of oocytes extracted from the ovaries was approximately $125( \pm 5) \mu \mathrm{m}$. However, many oocytes were considerably smaller ranging in size under $100 \mu \mathrm{m}$. Even in the oocytes that were larger than $100 \mu \mathrm{m}$, artificial fertilization was only moderately successful with fertilization rates never exceeding $50 \%$. However, the portion of largest oocytes was not considerably higher at the time the highest rate of developing zygotes was achieved in August 2013. Of the artificially inseminated zygotes a portion of approximately $20 \%$ developed irregularly. Together the findings indicate that only a fraction of the oocytes had been mature at the time of artificial fertilization. Thus, regular development could only be assumed when the larvae began to swim which was at approximately $20 \mathrm{~h}$ after fertilization.

\section{Early larval development}

Normally developing specimens rise up to become located just underneath the water surface while irregularly developing embryos remain situated on the bottom of the culturing container swimming in tight circles. Cleavage stages were not studied as it would have led to additional loss of already scarce developmental stages needed for observations of later stages of development. During further development it was impossible to offer any appropriate food to sustain the larvae. Absence of appropriate food resulted first in arrested development and soon after in degeneration of the larvae. However, the degree of degeneration differed individually within each batch and between batches resulting in different sizes and progress of the developmental stages. From the onset of starving (approximately after the third day of development) the descriptions refer to the most advanced stages observed on the respective day (Table 1 ).

Twenty hours after fertilization (20-hpf) the first embryos start to swim. The swimming behavior is not particularly directional resulting in most of the embryos moving in wide circles close to the water surface. At this time the embryo is a ciliated blastula without any conspicuous invaginations. Immunohistochemistry reveals signals of acetylated $\alpha$-tubulin like immunoreactivity $(\alpha$-tub-lir) on the surface of the embryo. These signals are indicative of comparatively short cilia adorning the ectodermal cells. At one pole of the embryo there is a region lacking $\alpha$-tub-lir signals representing the site of the prospective blastopore (Fig. 1a). In some more advanced embryos the aciliated area forms a shallow dimple indicating the onset of gastrulation (not shown). An apical tuft of elongated cilia is absent from this developmental stage (Fig. 1a).

After 1 day of development $(1-d p f)$ gastrulation is complete in all regularly developing specimens. Swimming behavior of the larvae has not considerably

Table 1 Timetable of developmental stages of Carinia ochracea reached by most of the larvae observed at $18{ }^{\circ} \mathrm{C}$ counted after artificial fertilization

\begin{tabular}{|c|c|}
\hline $\begin{array}{l}\text { Time after fertilization } \\
\text { (figure reference) }\end{array}$ & Structures observed in developmental stage \\
\hline 20-hpf (Fig. 1a) & Hatching, onset of gastrulation \\
\hline 1-dpf (Figs. 1b, 2a, 3a) & Gastrulation completed, frontal epidermal invaginations formed, formation of midgut cilia \\
\hline 2-dpf(Figs. 2b, 3b) & formation of apical tuft of elongated cilia, mouth opening begins to move frontally \\
\hline 3-dpf (Figs. 1c, 2c, 3c) & $\begin{array}{l}\text { Larva begins to elongate, mouth opening more frontal, midgut lumen with cilia visibly enlarged, muscular contractions observ- } \\
\text { able, neurites of central nervous system detectable, nephridia detectable, pigmented eye begins to form ventro-laterally }\end{array}$ \\
\hline $4-d p f$ (Fig. 2d) & pigmented eye enlarged, frontal epidermal invaginations more posterior and less deep \\
\hline 5-dpf (Figs. 2e, 3d) & $\begin{array}{l}\text { Further elongation of larva, becomes more slender, pigmented eye further enlarged and closer to ventral midline, frontal epider- } \\
\text { mal invaginations less deep }\end{array}$ \\
\hline 7-dpf (Figs. 2f, 3e) & Further elongati on of larva, pigmented eye further enlarged and situated almost on the ventral midline, midgut visibly empty, \\
\hline 10-dpf (Fig. 1d) & $\begin{array}{l}\text { No further progress in development, considerable fraction of larvae degenerate because of starvation, no settlement } \\
\text { observed }\end{array}$ \\
\hline
\end{tabular}



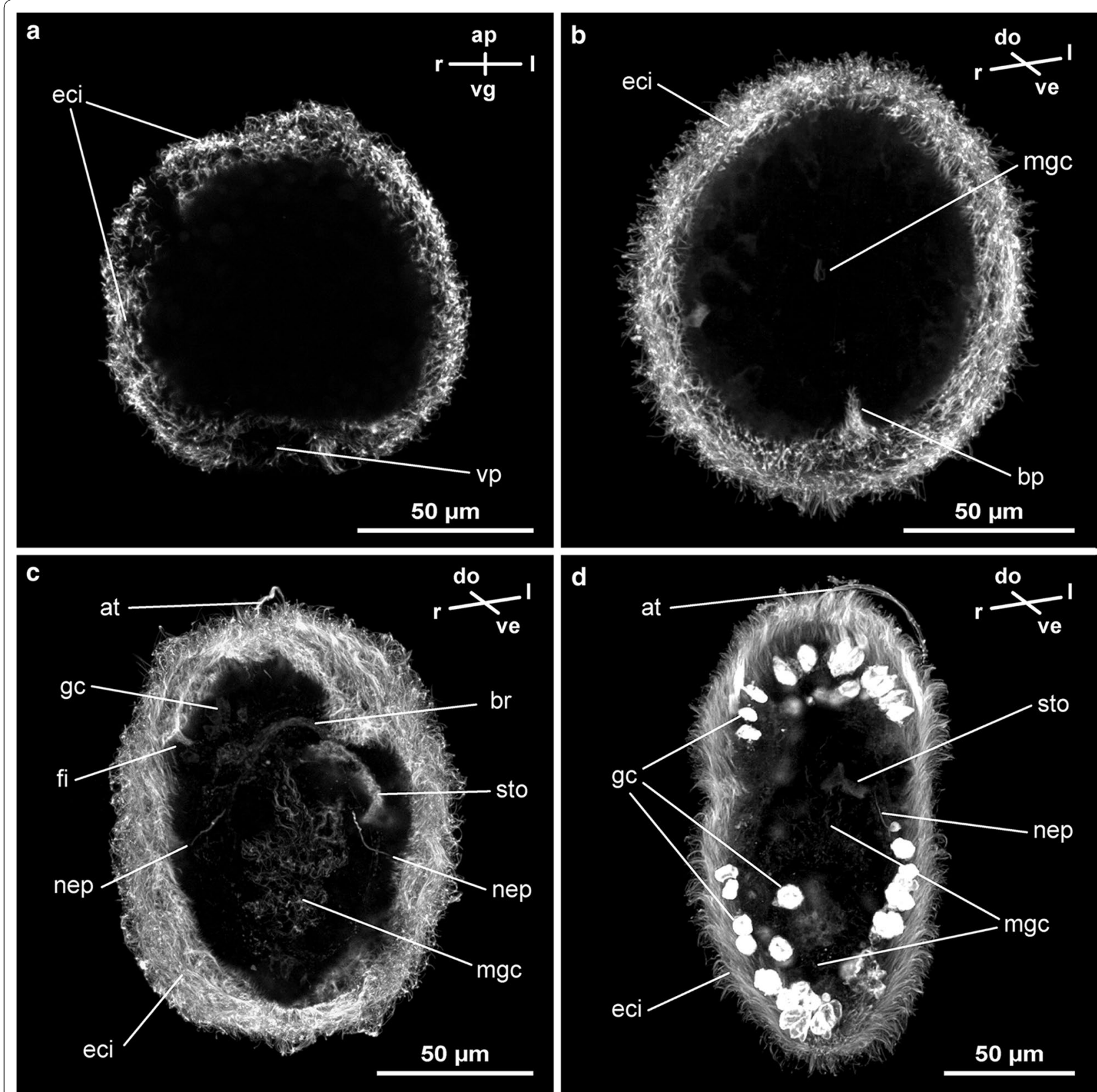

Fig. 1 Confocal z-projections of subsets of z-stacks of developmental stages of Carinina ochracea stained with antibodies against acetylated a-tubulin (orientation indicated by compass, apical/frontal is up, upper and lower sections omitted to make internal structures visible). a 20-hpf $(17.6 \mu \mathrm{m}$ of $54.56 \mu \mathrm{m}$ projected) newly hatched embryo, apart from the vegetal pole the surface is uniformly ciliated. b $1-d p f(26.4 \mu \mathrm{m}$ of $54.56 \mu \mathrm{m}$ projected) complete gastrula, the epidermis and the blastopore are uniformly ciliated, the archenteron shows faint ciliary signals. c $3-d p f(33.44 \mu \mathrm{m}$ of $52.8 \mu \mathrm{m}$ projected) feeding larva, an apical tuft of elongated cilia has formed, the frontal epidermal invaginations are clearly visible. The stomodaeum shows the same ciliation as the epidermis, while the midgut cilia are less densely set. Internally the neurites of the brain ring and the ciliated nephridia are visible. Note the unspecific signals of epidermal mucus gland cells frontal of the brain ring. d 10-dpf (22 $\mu \mathrm{m}$ of $45.76 \mu \mathrm{m}$ projected) most advanced larval stage observed, the epidermis and the stomodaeum are uniformly ciliated apart from the apical tuft of elongated cilia. The nephridia (only left side shown) and the midgut cilia appear less bright due to strong unspecific signal of the epidermal gland cells obscuring the internal structures. ap: apical, at: apical tuft, bp: blastopore, br: brain ring, do: dorsal, eci: epidermal cilia, fi: frontal epidermal invaginations, gc: mucus gland cells, l: left, mgc: midgut cilia, nep: nephridium, $r$ : right, sto: stomodaeum, ve: ventral, vg: vegetal, vp: vegetal pole 
changed although it appears livelier. As indicated by $\alpha$-tub-lir signals, the epidermis of the roughly spherical larva is evenly ciliated. The blastopore which will become the mouth opening is situated at the prospective caudal end of the larva. An apical tuft of elongated cilia was not observed. Inside the larva there are faint $\alpha$-tub-lir signals detectable. They represent the first cilia of the midgut primordium (Fig. 1b). The cells forming the midgut primordium are loaded with yolk resulting in a comparably narrow midgut cavity. There is an open connection between the blastopore and the midgut cavity (Figs. 2a, 3a). A pair of narrow epidermal

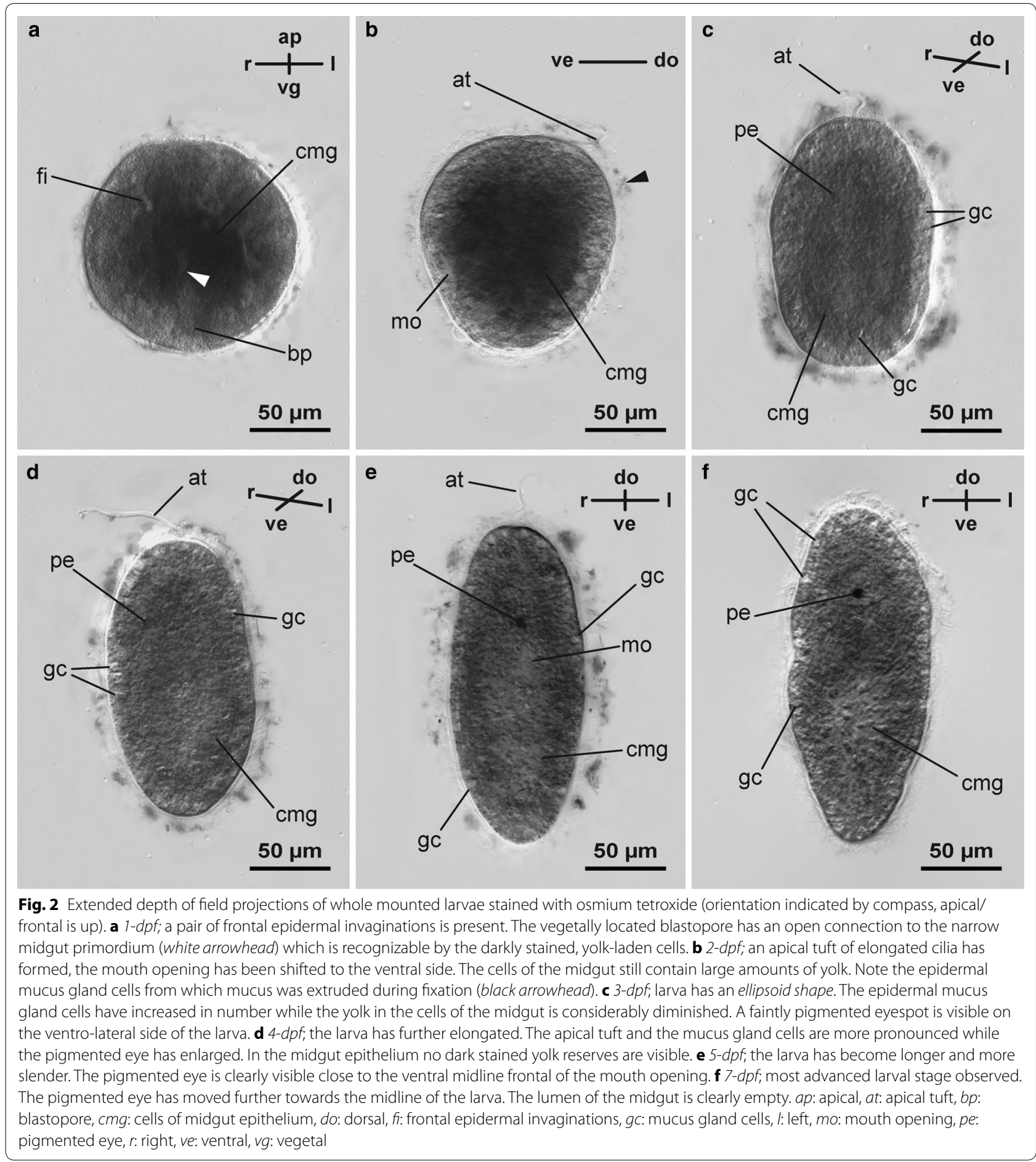




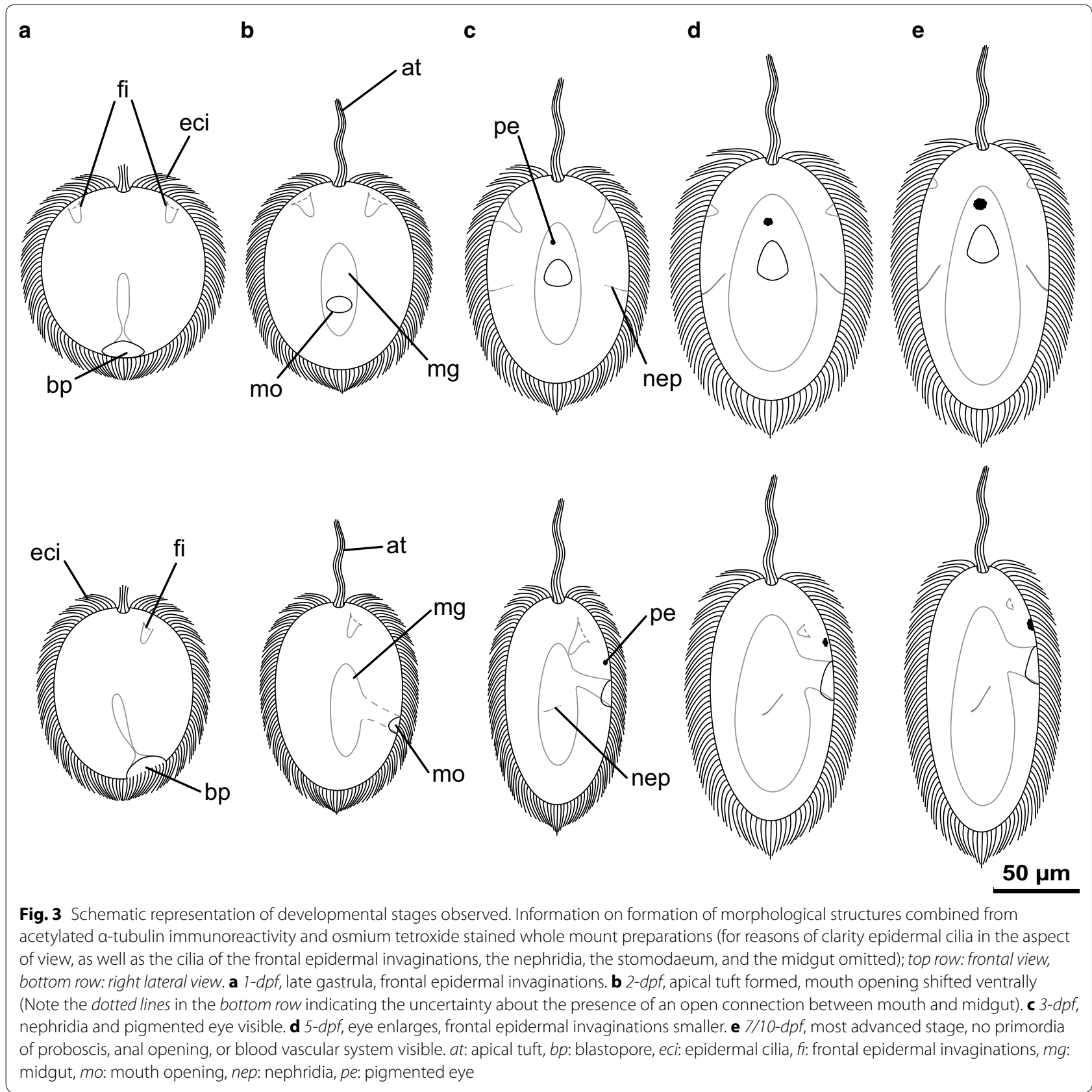

invaginations is located bilaterally on the pole of the larva that is opposite to the blastopore (frontal invaginations, Figs. 2a, 3a). In more advanced larval stages the blastopore is slightly shifted toward the future ventral side of the larva (Fig. 3a).

During further development the larva gradually stretches to become ellipsoid but with a blunter anterior end by 2 days after fertilization (2-dpf, Figs. 2b; 3b). The swimming behavior of the larvae is more directional resulting in the larvae moving in wide arches mostly keeping close to the water surface. By this time the mouth opening is located in a more anterior position on the ventral side of the larva (Figs. 2b, 3b). With the methods employed in this study it is impossible to decide whether the connection between the mouth and the midgut cavity is closed. On the blunt pole of the larva located between the lateral frontal invaginations the apical pit has formed from which a tuft of elongated cilia emanate (Figs. 2b, $3 b)$. In the epidermis large, refractive structures are visible that represent gland cells secreting sticky mucus that is extruded upon fixation. The secreted mucus causes the larvae to adhere to each other and even to the walls of the 
coated containers that they were fixed in. The secondary antibodies used in immunohistochemical staining also bind to the mucus resulting in the gland cells giving a non-specific signal under fluorescent light. In specimens stained with osmium tetroxide the extruded mucus shows up as dark flakes located between the epidermal cilia (Fig. 2b).

\section{Organogenesis}

After 3 days of development (3-dpf) the larval body has elongated while having become more slender. It now shows an even more ellipsoid outline (Figs. 2c, 3c). The swimming behavior of the larvae changes: They swim at higher speed in a straight line and a rotation around the longitudinal axis becomes apparent. Occasionally contractions of the larval body become evident, indicating the presence of functional musculature. Additionally, the association to the vicinity of the water surface is given up in that the larvae traverse the entire depth of the culturing container. At the apical pole of the larva the apical tuft and the lateral frontal invaginations have not changed considerably in shape or position. The mouth opening has moved further to the anterior pole, occupying a position in the anterior half of the larva (Figs. 1c, 3c). Furthermore, an open connection between the mouth opening and the now more enlarged midgut cavity is observable (Fig. 3c). As indicated by $\alpha$-tub-lir signals the ciliation of the midgut epithelium is clearly visible although not as densely set as the epidermal cilia or the cilia of the stomodeum (Fig. 1c). Together with the open connection to the mouth this indicates that the larva is ready to feed. Analogously, the darkly stained yolk material present in the midgut of younger developmental stages stained with osmium tetroxide is not detectable in 3-dpf larvae (Fig. 2c). The uniform, lighter staining with osmium tetroxide observed in 3-dpf stages indicates that the supply of yolk from the oocyte is exhausted. In front of the mouth opening a single pigmented eye with an irregular, roughly circular outline is visible. In most preparations studied it is situated close to the ventral midline but slightly displaced to the right (Figs. 2c, 3c). The midgut starts extending anteriorly beyond the level of the eye and mouth opening (Fig. 3c). In a bilateral position on the level of the mouth opening a pair of nephridia is indicated by $\alpha$-tub-lir inside the larva. Each nephridium has the shape of a narrow, unbranched, ciliated tube that runs from the mesodermal tissues through the epidermal cell layer to open to the dorso-lateral surface of the larva (Figs. 1c, 3c). Anterior to the mouth opening the tubulin containing neurites of the developing brain ring are visible by $\alpha$-tub-lir (Fig. 1c). The increasing number of gland cells in the larval epidermis is paralleled by an increase in number of unspecific signals in fluorescent preparations (Figs. 1c, 2c).
In 4-day old (4-dpf) larvae the body has stretched further and the apical pole has become narrower. Thus, the frontal epidermal invaginations have moved slightly posteriad and have become less deeply invaginated than in $3-d p f$ stages. They are now on the lateral side of the larva on the level of the brain ring. The apical tuft and the eye are still observable (Fig. 2d). While the apical tuft has not changed in size the eye has become considerably larger, being almost twice the size of the eye in 3-dpf larvae (Fig. 2d). Moreover it is now located closer to the ventral midline.

During the following days of development the larvae further elongate. The frontal epidermal invaginations become less deep and the pigmented eyespot becomes more evident frontal of the mouth opening (Figs. 2e, f, $3 \mathrm{~d}, \mathrm{e})$. At 7-dpf and onward, there is a slight constriction in the width of the body observable just posterior to the mouth opening in some specimens (Figs. 1d, 2f). Additionally, the posterior end of the body is tapering to a bluntly pointed tip (Fig. 2f). For this reason, a tuft of slightly elongated cilia becomes especially apparent at the caudal tip of the larva. The pigmented eye spot also increases in size and becomes darker. It is thus well visible even in specimens stained with osmium tetroxide from 5-dpf onward (Figs. 2e, f, 3d, e). While the position of the eye remains constant along the longitudinal axis of the larva it shifts its position in the lateral aspect to a more median position. At 7-dpf, the eye is located almost on the midline of the body (Figs. 2f, 3d).

The most advanced stages found at 10-dpf are very similar to the 7-dpf stages indicating arrested development due to lack of appropriate food (Figs. 1d, 2f). In the most advanced stages documented there are still epidermal mucus gland cells showing unspecific fluorescent signals (Fig. 1d). They obscure some of the internal, specific $\alpha$-tub-lir signals, such as the midgut cilia and the neurites of the central nervous system. On the contrary, the $\alpha$-tub-lir signals outlining epidermal cilia, the apical tuft, the nephridia, and the mouth opening are well visible (Fig. 1d). Even in the most advanced stages none of the primordia of the proboscis apparatus (including rhynchodaeum, rhynchocoel, and proposcis proper), the anus or the blood vascular system were detectable (Figs. 2f, 3e). Although sediment from the sand-flat that the adults were found in was supplied, none of the larvae were observed to settle.

After 10- $d p f$ no further progress in development was observed. Instead, all larvae showed signs of degeneration and successively disappeared from the culturing containers. Although a few larvae could still be found after 14 days of development their size had diminished to the size of 5-dpf stages. Therefore, development is not documented beyond this point. Accordingly, rearing of 
C. ochracea through metamorphosis cannot be considered successful.

\section{Discussion}

\section{Reproductive biology of Carinina ochracea}

Although natural spawning of Carinina ochracea was never observed during the course of this study some assumptions on the reproductive biology of this species can be made. Carinina ochracea is a dioecious species with males and females being of roughly the same size [37].The egg size of approximately $125 \mu \mathrm{m}$ is well within the range of egg sizes reported for anoplan nemerteans that develop from pelagic larvae $[10,36]$. As in the majority of nemertean species, mature eggs in the gonad are arrested in the prophase of the first meiotic division indicated by the germinal vesicle $[34,36]$. The sperm head is of a compact, almost spherical shape and measures 1.76 $( \pm 0.14) \mu \mathrm{m}$ in length and $1.61( \pm 0.14) \mu \mathrm{m}$ in width (published erroneously as Tubulanus linearis in von Döhren et al. [41]). The compact shape of the sperm heads along with the thin vitelline membrane of the oocytes support the assumption that in C. ochracea fertilization is external [35]. The occurrence of both large and smaller oocytes within the same gonad over a period of several months as well as the observed motility of sperm during the same period of time indicates that not all gametes may be shed in one single spawning event. Instead, it is conceivable that only the fraction of oocytes that is mature is discharged several times over the course of the reproductive period. However, from the different fertilization successes observed in this study it is assumed that there is a peak of reproductive activity in late July to early August at the coast of Brittany, France.

\section{Comparative aspects of larvae in Paleonemertea}

According to most recent phylogenies of Nemertea based on large molecular datasets there are two robustly supported clades: Pilidiophora and Hoplonemertea. They are most likely united in the monophyletic clade Neonemertea while the remaining lineages form its sister as arguably monophyletic Palaeonemertea (sensu stricto) $[1,2,23]$. The majority of nemertean species is assumed to develop via pelagic larvae $([25,26,30,40]$, and references therein). While the canonic larva of Pilidiophora is the pilidium, the larval type of Hoplonemertea has more recently been termed decidula larva [25]. Both larval types have in common that the larval epidermis is of transitory nature and will be replaced by the definite epidermis of the juvenile later during development $[15$, 24, 25, 27 and references therein]. Based on comparable expression patterns of $\mathrm{Hox}, \mathrm{Cdx}$, and Six $3 / 6$ genes during development certain invaginations of the larval epidermis have been hypothesized as a shared derived character in
Pilidiophora and Hoplonemertea (viz. Neonemertea) [13, 14]. The larval type of Palaeonemertea is not that well characterized. Of the four monophyletic palaeonemertean lineages recovered in recent molecular phylogenetic analyses Carinina is the only one from which the larval type has not been described in detail so far. Filling the gap with data from this study permits for comparative characterization of the larval types in palaeonemertea. The larva of $C$. ochracea develops cilia and hatches prior to the onset of gastrulation. The same has been described in the pilidiophoran species Micrura alaskensis while in other palaeonemertean and pilidiophoran larvae hatching has been described to take place after gastrulation $[4,16,17,24,28,33]$. In newly hatched embryos of $C$. ochracea an apical tuft of longer cilia has not yet formed. Congruently to what has been described in most palaeonemertean species, a bilateral pair of frontal epidermal invaginations is present before the apical tuft is formed [17].

The invaginations have variously been interpreted as primordia of either the brain or the cerebral organ canals $[10,13,15,17,27,28]$. Similar frontal epidermal invaginations are reported from developmental stages of several mollusk species in which they have been identified as first rudiments of the neuroectoderm from which the cerebral ganglia develop [20,31,32]. On the other hand, epidermal invaginations that develop into the cerebral organ canals independent of the brain have been observed in the hoplonemertean species Paranemertes peregrina [27]. In order to clarify the identity of the bilateral epidermal invaginations as primordia of either the nervous system or the cerebral organ canals further comparative developmental data is needed especially on more advanced nemertean larval stages. Regardless of their identity it has to be assumed, based on current phylogenetic hypotheses that the early formed frontal epidermal invaginations found in palaeonemertean and hoplonemertean species represent an ancestral trait in nemertean development.

In C. ochracea the development from the gastrula to the larva is similar to that described in other palaeonemertean species and includes the translocation of the mouth opening to the ventral side of the body $[17,19$, 28]. Likewise, an apical tuft of elongated cilia housed in a shallow epidermal depression is present after the first day of development [30]. On the level of the mouth opening a pair of simple unbranched nephridia is detectable by their ciliation after 3 days of development. They seem to be composed of only a few cells and thus most likely correspond to the type of nephridia described in other palaeonemertean larvae [3]. At the same time a single pigmented eye is formed on the ventro-lateral right side of the larva close to the midline. The eye becomes larger 
during further development while there are no additional pigmented eyes detectable. Despite its enlargement, it has to be assumed that the eye in C. ochracea is a transitory larval organ since eyes are absent from adult specimens [37]. This finding is in line with circumstantial evidence that the eyes are transitory larval organs absent from adults in all palaeonemertean species investigated so far [11, 39]. A single ventral eye has so far been reported only from the larvae of Carinoma species which, likewise, are eyeless as adults $[3,12,28,30$, 39]. The larva of Tubulanus punctatus is reported to lack eyes while there is a pair of dorso-laterally located eyes in larvae of Cephalothrix (Procephalothrix) species [17, 33, 39]. In the most recently published image of the larva of an unidentified Callinera species a pigment spot is visible that could be interpreted as a single pigmented eye [7]. Whether this eye is situated on the dorsal or on the ventral side could not be determined from the published image. An alternative source depicts a larva of an unidentified Callinera species without eyes [21]. Since, according to most recent molecular phylogenies, Callinera is an ingroup of Tubulanus it is more likely that larvae of Callinera species lack eyes altogether $[1,23]$. The occurrence of a single, larval eye in larvae of Carinoma and Carinina species is supportive of a close affinity of these genera thus underpinning the results of most recent molecular phylogenetic analyses $[1,23]$.

The gut appears functional at the third day of development. At this stage the stomodaeum and the midgut can be distinguished by the difference in density of their ciliation. As pointed out by Iwata [17] the difference in ciliation is indicative of the stomodaeum being of ectodermal origin. However, it remains to be shown whether the blastopore is closed prior to this stage as has been reported from some palaeonemertean species $[17,33]$. Along with a functioning gut the larva of C. ochracea needs to take up food to accomplish further development. The food items offered during this study evidently fail to supply adequate nourishment so that no progress of development could be recorded after the first week. Adequate supply of food in cultured palaeonemertean larvae is generally a problem in virtually all reported studies $[17,28,33]$. It results in some aspects of later development, including metamorphosis and transition to benthic life not being documented for this group of species. Correspondingly, no information on the formation of the anus or the blood vascular system is documented for any palaeonemertean species. Of the proboscis apparatus which includes the rhynchodaeum, the rhynchocoel and the proboscis proper only the latter has been reported to start differentiating in very old larval stages of the palaeonemertean species Cephalothrix rufifrons [33]. Although Smith [33] identifies the first progenitor cells of the rhynchodaeum already in newlyhatched larvae, corresponding cell populations have not been reported in any other palaeonemertean species [17, 28]. In larvae of C. ochracea no primordia of any of the characteristic adult structures of Nemertea, i.e. blood vascular system, anal opening, or proboscis apparatus are detectable either.

In summary, the larval development of C. ochracea is largely similar to the development of the larvae of other palaeonemertean species. General aspects include the occurrence of a pair of frontal epidermal invaginations between which the apical pit with a tuft of elongated cilia develops, a sac-like midgut, the translocation of the mouth to the ventral side of the larva, the formation of simple nephridia composed of only a few cells, and the necessity to feed to further progress in development. It is noteworthy, that no preoral trochal bands of elongated cilia which are used for food capture in most other feeding trochozoan species are observed in any palaeonemertean larva [17, 25, 26, 30,33]. Regarding the development of internal structures such as the nervous system and musculature and the ultrastructure of arguably larval organs such as the eye and the nephridia, further studies are conducted and will be subject to upcoming publications.

\section{Acknowledgements \\ I would like to express my gratitude to the colleagues of the Institute of Evo- lutionary Biology and Ecology of Bonn University, Germany. I am especially obliged to Claudia Müller who performed the majority of immunostain- ing and confocal microscopy and to Tatjana Bartz for assistance with the osmium tetroxide staining of the larvae. I also would like to thank Jan-Philip Øyen whose bachelor thesis provided the framework for identifying Carinina ochracea from Concarneau. Furthermore, I would like to express my gratitude to the staff of the Station de Biologie Marine de Concarneau for offering hospitality during the collecting trips for C. ochracea. Further- more, two anonymous reviewers are kindly acknowledged for commenting on an earlier version of the manuscript. Finally, my sincere thanks go to \\ Thomas Bartolomaeus for helpful comments regarding the contents of the manuscript. \\ All applicable international, national, and/or institutional guidelines for the care and use of animals were followed.}

Competing interests

The author declares that he has no competing interests.

Received: 16 December 2015 Accepted: 9 May 2016

Published online: 01 December 2016

References

1. Andrade SCS, Strand M, Schwartz M, et al. Disentangling ribbon worm relationships: multi-locus analysis supports traditional classification of the phylum Nemertea. Cladistics. 2012;28:141-59.

2. Andrade SCS, Montenegro $\mathrm{H}$, Strand $\mathrm{M}$, et al. A transcriptomic approach to ribbon worm systematics (Nemertea): resolving the Pilidiophora problem. Mol Biol Evol. 2014;31:3206-15.

3. Bartolomaeus T, Maslakova SA, von Döhren J. Protonephridia in the larvae of the paleonemertean species Carinoma mutabilis (Carinomidae, Nemertea) and Cephalothrix (Procephalothrix) filiformis (Cephalothricidae, Nemertea). Zoomorphology. 2014;133:43-57. 
4. Beckers P, Bartolomaeus T, von Döhren J. Observations and experiments on the biology and life history of Riseriellus occultus (Heteronemertea: Lineidae). Zoolog Sci. 2015;546:531-46.

5. Bürger O. Die Nemertinen des Golfes von Neapel und der angrenzenden Meeresabschnitte. Berlin: Friedländer und Sohn; 1895.

6. Cantell CE. The devouring of larval tissues during metamorphosis of pilidium larvae (Nemertini). Ark För Zool. 1966;18:489-92.

7. Chernyshev AV. Comparative morphology, systematics and phylogeny of the nemerteans. Vladivostok: Dalnauka; 2011 (in Russian)

8. Dawydoff C. Sur l'embryologie des Protonémertes. CR Hebd Séances Acad Sci Paris. 1928:186:531-3.

9. Forster B, Van De Ville D, Berent J, et al. Complex wavelets for extended depth-of-field: a new method for the fusion of multichannel microscopy images. Microsc Res Tech. 2004;65:33-42.

10. Friedrich H. Morphogenese der Tiere. Nemertini, Lieferung 3: $D_{5}-1$. Jena: Gustav Fischer Verlag; 1979.

11. Gibson R. Nemerteans. London: Hutchinson University Library; 1972.

12. Griffin BB. Description of some marine nemerteans of Puget Sound and Alaska. Ann N Y Acad Sci. 1898;11:193-217.

13. Hiebert LS, Maslakova SA. Expression of Hox, Cdx, and Six3/6 genes in the hoplonemertean Pantinonemertes californiensis offers insight into the evolution of maximally indirect development in the phylum Nemertea. Evodevo. 2015;6:26.

14. Hiebert LS, Maslakova SA. Hox genes pattern the anterior-posterior axis of the juvenile but not the larva in a maximally-indirect developing invertebrate, Micrura alaskensis (Nemertea). BMC Biol. 2015:13:1-12.

15. Hiebert LS, Gavelis G, von Dassow G, Maslakova SA. Five invaginations and shedding of the larval epidermis during development of the hoplonemertean Pantinonemertes californiensis (Nemertea: Hoplonemertea). J Nat Hist. 2010;44:2331-47.

16. Iwata F. On the development of the nemertean Micrura akkeshiensis. Embryologia. 1958;4:103-31.

17. Iwata F. Studies on the comparative embryology of nemerteans with special reference to their interrelationships. Publ Akkeshi Mar Biol Stn. 1960;10:1-55.

18. Iwata F. The life history of the Nemertea. Bull Biol Stn Asamushi. 1960:10:95-7.

19. Iwata F. Foregut formation of the nemerteans and its role in nemertean systematics. Am Zool. 1985;25:23-36.

20. Jacob MH. Neurogenesis in Aplysia californica resembles nervous system formation in vertebrates. J Neurosci. 1984;4:1225-39.

21. Jägersten G. Evolution of the metazoan life cycle. London: Academic Press; 1972

22. Kajihara H, Chernyshev AV, Sun S-C, et al. Checklist of nemertean genera and species published between 1995 and 2007. Species Divers. 2008;13:245-74.

23. Kvist S, Laumer CE, Junoy J, Giribet G. New insights into the phylogeny, systematics and DNA barcoding of Nemertea. Invertebr Syst. 2014;28:287-308.

24. Maslakova SA. Development to metamorphosis of the nemertean pilidium larva. Front Zool. 2010;7:30.
25. Maslakova SA. The invention of the pilidium larva in an otherwise perfectly good spiralian phylum Nemertea. Integr Comp Biol. 2010:50:734-43.

26. Maslakova SA, Hiebert TC. From trochophore to pilidium and back again —a larva's journey. Int J Dev Biol. 2014;58:585-91.

27. Maslakova SA, von Döhren J. Larval development with transitory epidermis in Paranemertes peregrina and other hoplonemerteans. Biol Bull. 2009;216:273-92.

28. Maslakova SA, Martindale MQ, Norenburg JL. Vestigial prototroch in a basal nemertean, Carinoma tremaphoros (Nemertea; Palaeonemertea). Evol Dev. 2004;6:219-26.

29. Maslakova SA, Martindale MQ, Norenburg JL. Fundamental properties of the spiralian developmental program are displayed by the basal nemertean Carinoma tremaphoros (Palaeonemertea, Nemertea). Dev Biol. 2004:267:342-60

30. Norenburg JL, Stricker SA. Phylum Nemertea. In: Young CM, editor. Atlas of marine invertebrate larvae. San Diego: Academic Press; 2002. p. 163-77.

31. Okusu A. Embryogenesis and development of Epimenia babai (Mollusca Neomeniomorpha). Biol Bull. 2002;203:87-103.

32. Page R. New interpretation of a nudibranch central nervous system based on ultrastructural analysis of neurodevelopment in Melibe leonina. I. Cerebral and visceral loop ganglia. Biol Bull. 1992;182:348-65.

33. Smith JE. Memoirs: the early development of the nemertean Cephalothrix ruffrons. Q J Microsc Sci. 1935;2:335-81.

34. Stricker SA. Calcium signaling and endoplasmic reticulum dynamics during fertilization in marine protostome worms belonging to the phylum Nemertea. Biochem Biophys Res Commun. 2014;450:1182-7.

35. Stricker SA, Folsom MW. A comparative ultrastructural analysis of spermatogenesis in nemertean worms. Hydrobiologia. 1997;365:55-72.

36. Stricker SA, Smythe TL, Miller L, Norenburg JL. Comparative biology of oogenesis in nemertean worms. Acta Zool. 2001;82:213-30.

37. Sundberg $\mathrm{P}$, Chernyshev AV, Kajihara $\mathrm{H}$, et al. Character-matrix based descriptions of two new nemertean (Nemertea) species. Zool J Linn Soc. 2009;157:264-94.

38. Thollesson M, Norenburg JL. Ribbon worm relationships: a phylogeny of the phylum Nemertea. Proc Biol Sci. 2003;270:407-15.

39. von Döhren J (2008) Zur Phylogenie der Nemertea: Vergleichende Untersuchungen der Reproduktion und Entwicklung. Dissertation, Freie Universität Berlin.

40. von Döhren J. Nemertea. In: Wanninger A, editor. Evolutionary developmental biology of invertebrates, vol. 2., Lophotrochozoa (Spiralia)Wien: Springer; 2015. p. 155-92.

41. von Döhren J, Beckers P, Vogeler R, Bartolomaeus T. Comparative sperm ultrastructure in Nemertea. J Morphol. 2010;271:793-813.

42. Schindelin J, Arganda-Carreras I, Frise E, Kaynig V, Longair M, Pietzsch T, et al. Fiji: an open-source platform for biological-image analysis. Nat Methods. 2012;9:676-82.

\section{Submit your next manuscript to BioMed Central and we will help you at every step:}

- We accept pre-submission inquiries

- Our selector tool helps you to find the most relevant journal

- We provide round the clock customer support

- Convenient online submission

- Thorough peer review

- Inclusion in PubMed and all major indexing services

- Maximum visibility for your research

Submit your manuscript at www.biomedcentral.com/submit
BioMed Central 